\title{
Subclinical endocrinological disease
}

Series editor: Dr $\mathcal{F W F}$ Elte, Department of Internal Medicine, Sint Franciscus Gasthius, Rotterdam, The Netherlands

\section{Impaired glucose tolerance and unidentified diabetes}

\author{
Robert J Heine, Johanna M Mooy
}

\begin{abstract}
Summary
The epidemiology of impaired glucose tolerance and undiagnosed non-insulin-dependent diabetes mellitus is reviewed and the implications for screening strategies discussed.
\end{abstract}

Keywords: glucose tolerance, diabetes mellitus screening

Table 1 Diagnostic values for the oral glucose tolerance test. Glucose concentrations $(\mathrm{mmol} / \mathrm{l})$ in venous plasma

\begin{tabular}{lll}
\hline & $\begin{array}{l}\text { Fasting } \\
\text { value }\end{array}$ & $\begin{array}{l}2 \mathrm{~h} \text { after } \mathrm{a} \\
75 \mathrm{~g} \text { glucose } \\
\text { load }\end{array}$ \\
\hline $\begin{array}{l}\text { Diabetes mellitus } \\
\begin{array}{l}\text { Impaired glucose } \\
\text { tolerance }\end{array}\end{array}$ & $<7.8$ & $\geqslant 11.1$ \\
\hline
\end{tabular}

Table 2 Prevalence of NIDDM in comparable age groups in caucasian populations

\begin{tabular}{ll}
\hline Country & $\begin{array}{l}\text { Prevalence of NIDDM } \\
(\%)\end{array}$ \\
\hline Age 55-64 years & \\
The Netherlands & 8 \\
Sweden & 6 \\
USA & 13 \\
Age 65-74 years & \\
The Netherlands & 13 \\
Sweden & 14 \\
USA & 18 \\
Finland & 17 \\
\hline
\end{tabular}

Department of Endocrinology and Institute for Research in Extramural Medicine, Vrije Universiteit Amsterdam, PO Box 7057, 1007 MB Amsterdam, The Netherlands RJ Heine JM Mooy
Non-insulin-dependent diabetes mellitus (NIDDM) is a frequently occurring chronic disease, particularly common in the population over 40 years of age. Several recent population-based studies have also demonstrated high prevalence rates of impaired glucose tolerance and undiagnosed NIDDM. One reason that NIDDM remains undetected may be the absence of specific symptoms.

Retinopathy is present at the time of diagnosis in a considerable proportion $(15-30 \%)$ of patients, indicating the seriousness of this condition and the long duration of prevailing high blood glucose levels. Thus, because of the inability to diagnose and adequately treat this silent hyperglycaemia, the devastating complications of diabetes are allowed to develop. Moreover, impaired glucose tolerance and NIDDM are associated with metabolic abnormalities, such as the insulin resistance syndrome, which confers a seriously elevated risk for cardiovascular morbidity and mortality.

\section{Definitions}

The criteria used to diagnose diabetes and impaired glucose tolerance were recommended by the WHO in $1985 .^{1}$ These criteria were originally based on longitudinal studies in the US and UK which demonstrated that subjects with 2-h post-challenge glucose values above $200 \mathrm{mg} / \mathrm{dl}(11.1 \mathrm{mmol} / \mathrm{l})$ were at risk of developing diabetes-related complications (table 1 ).

\section{Epidemiology}

In recent years, interest in the epidemiology of impaired glucose tolerance and NIDDM has grown tremendously, as reflected by the number of papers published. Population-based studies on the prevalence rates of impaired glucose tolerance and NIDDM have been reported both from the US and several European countries. ${ }^{2-5}$

In the US, representative data on undiagnosed NIDDM have been obtained through population-based surveys, (the second national health and nutrition examinations survey (NHANES), and the Hispanic health and nutrition examination survey). ${ }^{2}$

The Dutch study was conducted in 1989-91 in the city of Hoorn. ${ }^{5} \mathrm{~A}$ random sample of the population aged 50-74 years was drawn resulting in a sample of 3553 eligible subjects. Of these subjects 2540 persons $(71 \%)$ participated in the survey.

Remarkably, the prevalence rates of the various categories of glucose tolerance in the different countries are very similar, albeit that the prevalence rates of impaired glucose tolerance and NIDDM in the US are slightly higher, possibly because of greater obesity (table 2, figure 1). Moreover, the proportions of known diabetes mellitus, undiagnosed NIDDM and impaired glucose tolerance in the general population are strikingly similar: across all age groups and both genders, undiagnosed diabetes represents about half of all diabetes and the impaired glucose tolerance rate is slightly higher than for all diabetes.

The data for the US and The Netherlands indicate that a considerable proportion of the populations has a disease or risk condition, impaired glucose tolerance, that conveys increased morbidity and mortality, which nevertheless is untreated.

\section{Microvascular disease and undiagnosed abnormal glucose tolerance}

The major risk factors for developing microvascular diseases are hyperglycaemia and duration of diabetes. ${ }^{6}$ Blood pressure has been incriminated as a contributing 

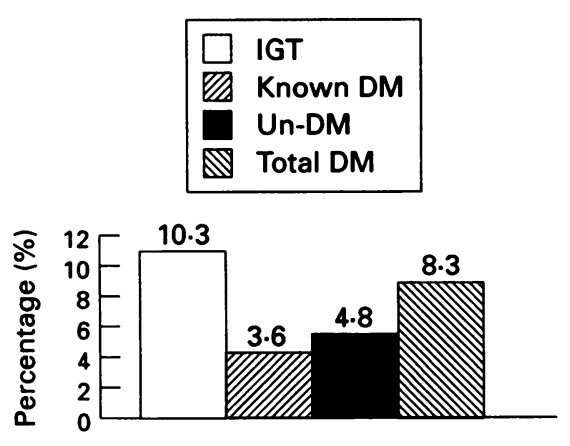

Figure 1 Prevalence of impaired glucose tolerance (IGT) and diabetes mellitus (DM) in a Dutch caucasian population aged between $50-75$ years. Un-DM $=$ undiagnosed diabetes mellitus. From ${ }^{5}$

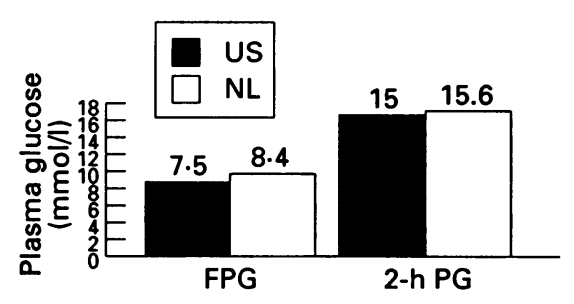

Figure 2 Fasting and 2-h plasma glucose values in undiagnosed NIDDM from US and Dutch studies. FPG $=$ fasting plasma glucose, 2-h PG $=2$-hour plasma glucose value. From ${ }^{8,9}$

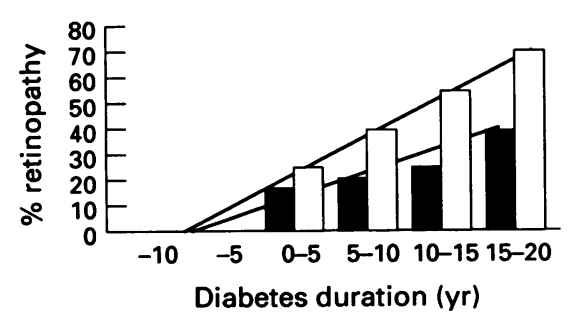

Figure 3 Estimate of the duration of diabetes between onset and clinical diagnosis: prevalence of any diabetic retinopathy since diagnosis. Top line: $\mathrm{US}^{10}$; bottom line: The Netherlands ${ }^{11}$

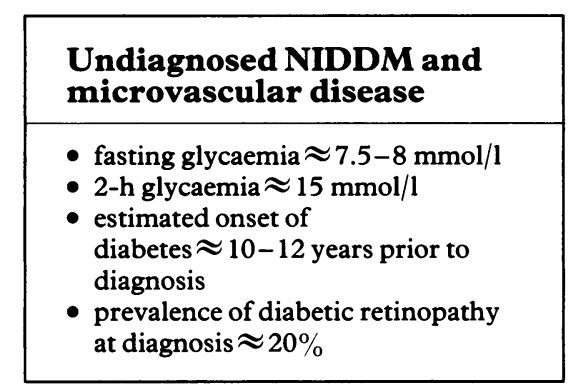

Box 1 factor in the progression of existing complications, and of diabetic retinopathy and nephropathy in particular. ${ }^{7}$

The mean fasting and $2-\mathrm{h}$ blood glucose levels in the undiagnosed diabetics in the US were both in a range which is considered an indication for treatment: 7.5 and $15 \mathrm{mmol} / \mathrm{l}$, respectively. ${ }^{8}$ In the Dutch study similar values were found in the newly diagnosed diabetics: $8.4 \pm 3.1$ and $15.6 \pm 5.5 \mathrm{mmol} / \mathrm{l}$, for the fasting and 2-h glucose values, respectively (figure 2 ).${ }^{9}$ These data, again, clearly show that individuals with undiagnosed diabetes have glycaemic levels that require treatment.

Considering these values it should be of no surprise that a considerable number of subjects with NIDDM harbour diabetes-related microvascular complications at diagnosis. Various studies have reported on the prevalence of diabetic retinopathy at diagnosis, which varies considerably, between 9.9 and $29 \%$. This variation is due primarily to the fact that these data are derived both from studies assessing the prevalence at clinical diagnosis and from populationbased surveys (box 1). . $^{8,10}$

Figure 3 shows a linear relationship between the frequency of diabetic retinopathy and known duration of NIDDM in two different populations, one from Southern Wisconsin, USA ${ }^{10}$ and the other from Amsterdam, The Netherlands. ${ }^{11}$ The intersect of these lines with the $\mathrm{X}$-axis indicates that diabetic retinopathy was present more than five years before the actual clinical diagnosis. From long-term follow-up studies it is known that retinopathy is not demonstratable in the first five years after the start of hyperglycaemia, thus the real onset of the diabetes may even be more than 10 years prior to the clinical diagnosis of NIDDM. ${ }^{12}$

\section{Macrovascular disease and undiagnosed abnormal glucose tolerance}

\section{RISK FACTORS}

The major known risk factors for the development and progression of cardiovascular disease include hyperglycaemia, the classic cardiovascular risk factors and insulin resistance. ${ }^{13}$ This latter condition, reflected by hyperinsulinaemia, is associated with several of the listed factors and in addition with compositional changes of the lipoproteins, disturbed fibrinolysis, and endothelial dysfunction (box 2). ${ }^{14-17}$

Most of these risk factors have been demonstrated to be already present in subjects with impaired glucose tolerance and undiagnosed diabetes. ${ }^{8,9-18}$ Table 3 depicts the prevalence of some of the classic risk factors for subjects with normal glucose tolerance, undiagnosed NIDDM and known diabetes in a Dutch elderly (50-75 years) population. ${ }^{19}$ Two things are apparent: hypercholesterolaemia is very prevalent and not associated with glucose tolerance, whereas hypertension, hypertriglyceridaemia and low high-density lipoprotein (HDL) cholesterol is two- to three-fold more prevalent in undiagnosed and known diabetes.

These data are remarkably similar to those reported for the US population. Moreover, obesity, and in particular central obesity (high waist-to-hip ratio), is very prevalent and an important determinant of cardiovascular risk factors associated with insulin resistance. ${ }^{18,19}$

\section{MACROVASCULAR DISEASE IN UNDIAGNOSED DIABETES}

In the Hoorn survey special attention was paid to the cross-sectional association between glucose tolerance and the prevalence of vascular disease. From previous studies it was known that atherosclerotic vascular disease manifesting itself as coronary heart disease, carotid artery disease and peripheral arterial disease is markedly increased in subjects with abnormal glucose tolerance. ${ }^{13}$ Peripheral

Table 3 Prevalence ( $\%$ ) of hypertension (treated and untreated), and dyslipidaemia for persons with normal, undiagnosed (un-NIDDM) and diagnosed NIDDM

\begin{tabular}{llll}
\hline & $\begin{array}{l}\text { Normal glucose } \\
\text { tolerance }\end{array}$ & Un-NIDDM & NIDDM \\
\hline Hypertension $(\geqslant 160 / 95 \mathrm{mmHg})$ & & & \\
$\quad$ untreated & 7 & 16 & 8 \\
$\quad$ treated & 17 & 36 & 49 \\
Hypercholesterolaemia $(>6.5 \mathrm{mmol} / \mathrm{l})$ & 55 & 56 & 36 \\
Hypertriglyceridaemia $(>2.2 \mathrm{mmol} / \mathrm{l})$ & 14 & 45 & 18 \\
Low HDL cholesterol $(<0.9 \mathrm{mmol} / \mathrm{l})$ & 9 & 18 & \\
\hline
\end{tabular}

$\mathrm{HDL}=$ high-density lipoprotein 


\begin{tabular}{|l|}
\hline Risk factors for \\
macrovascular disease in \\
NIDDM \\
\hline - hyperglycaemia \\
- hypertension \\
- dyslipidaemia: high LDL \\
cholesterol, hypertriglyceridaemia, \\
low HDL cholesterol, \\
compositional changes of \\
lipoproteins, eg, small dense LDL \\
- disturbed fibrinolysis \\
- smoking \\
hyperinsulinaemia, as a reflection of \\
insulin resistance \\
central obesity \\
LDL = low-density lipoprotein \\
HDL = high-density lipoprotein \\
\hline
\end{tabular}

Box 2

\begin{tabular}{|l|}
\hline The burden of undiagnosed \\
diabetes \\
\hline - $50 \%$ of all diabetes \\
microvascular disease, and in \\
particular diabetic retinopathy and \\
neuropathy present in $10-30 \%$ at \\
diagnosis \\
- $60-70 \%$ of all deaths due to \\
cardiovascular disease \\
- mortality rate $3-4$ times that of \\
non-diabetics \\
peripheral artery disease, expressed \\
as ankle brachial pressure index \\
< 0.90 in $15 \%$ of cases \\
modifiable risk factors for \\
cardiovascular disease $2-3$ times \\
more prevalent than in non-diabetic \\
subjects \\
\hline
\end{tabular}

Box 3

\begin{tabular}{|l|}
\hline $\begin{array}{l}\text { Treatment modalities and } \\
\text { preventive strategies in } \\
\text { abnormal glucose tolerance }\end{array}$ \\
\hline - lifestyle changes: cessation of \\
smoking, improved nutritional \\
habits (less saturated fat, energy \\
restriction in the obese), more \\
physical exercise \\
- blood glucose lowering agents \\
- antihypertensives \\
lipid-lowering agents \\
\hline
\end{tabular}

Box 4

\begin{tabular}{l} 
Arguments in favour of \\
early intervention \\
\hline Shorter exposure to risk factors for: \\
- microvascular disease \\
and cardiovascular disease \\
- preservation of $\beta$-cell function \\
- improvement of insulin sensitivity \\
\hline
\end{tabular}

Box 5 vascular disease, defined as an ankle brachial pressure index of less than 0.90 , was twice as prevalent in the undiagnosed diabetics as in subjects with normal glucose tolerance $(15.1 \%$ vs $7 \%$ ). Peripheral arterial disease was found to be associated with indices of glycaemic control, smoking behaviour, and hypertension. ${ }^{9}$

Repeatedly and consistently it has been shown that the mortality rate is higher in subjects with abnormal glucose tolerance than in non-diabetic subjects. A recent example is the Paris prospective study which demonstrated a 2.5 -fold higher mortality rate during an 11-year follow-up study in subjects with undiagnosed NIDDM as opposed to subjects with normal glucose tolerance (23 vs $9 \%$ ).$^{18}$ The mortality in the diagnosed diabetics was $20 \%$, thus lower or at the most similar to those with undiagnosed NIDDM. This trend to a higher mortality in the undiagnosed may be due to the lack of treatment of associated risk factors such as high blood pressure, hyperglycaemia, and dyslipidaemia. The prospective Whitehall study with 15 years of follow-up presented similar results: per 1000 person years 12 non-diabetics, 40 undiagnosed and 27 diagnosed persons died. It is important to note that the vast majority of the diagnosed and undiagnosed died of cardiovascular disease $(60-70 \%)$.

From these data it is clear that the excess mortality is mostly due to atherogenic vascular disease. In several studies high insulin levels have been found to be associated with an increased risk for coronary heart disease, suggesting that either insulin per se or insulin resistance may be atherogenic. ${ }^{13-15,22}$ This controversy is still very much alive. More and more arguments point, however, to the fact that insulin levels should be considered a compensatory phenomenon for insulin resistance. This in turn is associated with a number of abnormalities, comprising a now well-recognised syndrome, the insulin resistance syndrome, which is a coronary heart disease risk factor. As mentioned earlier, of special interest are the compositional changes in lipoproteins and the disturbances in the fibrinolytic process and changes that promote thrombus formation by increasing coagulation. Further evidence for the importance of the insulin resistance syndrome emerged from the Paris prospective study, where a high waist-to-hip ratio (thus android fat distribution), and hypertriglyceridaemia were the strongest predictors of coronary heart disease mortality in diabetic and glucoseintolerant subjects. ${ }^{23}$

Taken together, undiagnosed diabetes is a large and still growing problem throughout the world. The major characteristics of this highly underestimated burden are depicted in box 3 .

\section{Early detection and treatment}

\section{ARGUMENTS FOR EARLY DETECTION}

Since undiagnosed diabetes is a highly prevalent condition responsible for a high morbidity and mortality, preventive measures have to be considered. From the foregoing it also is clear that in the undiagnosed diabetic subject, various risk factors, associated with insulin resistance, are present, for which adequate treatment is available. Box 4 lists the management tools for the treatment of established NIDDM. The important point is that the inference is made that early treatment of the modifiable risk factors will result in a lower incidence of morbidity and mortality. There is overwhelming evidence from cross-sectional and prospective studies showing that the higher the glucose level the more likely it is that subjects will develop retinopathy, neuropathy and nephropathy. ${ }^{24,25}$ This situation is remarkably similar to that in the pre-Diabetes Control and Complications Trial era in IDDM. ${ }^{26}$

More complicated is the situation as to the cardiovascular risk. No long-term randomised clinical trials investigating the efficacy of an intervention on cardiovascular mortality have been performed in NIDDM subjects. Here also we have to consider the evidence from epidemiologic and observational studies, and the fact that several of the recognised cardiovascular risk factors respond favourably to appropriate treatment. Another possibly important consideration favouring early detection of NIDDM is the preservation of $\beta$-cell function. Chronic hyperglycaemia is known to influence adversely the two major pathogenic mechanisms, ie, $\beta$-cell function and insulin sensitivity. Therefore it may be assumed that earlier restoration of normoglycaemia will influence beneficially both of these mechanisms and impede further deterioration of the diabetic state (box 5$).^{27}$

\section{HOW TO DETECT UNDIAGNOSED NIDDM}

In recent years several strategies have been proposed for early detection of NIDDM. These proposals range from population screening to public awareness campaigns. ${ }^{8,28,29}$ Screening can be performed at different levels, eg, community screening or testing for diabetes in patients visiting the doctor's office. The latter 


\section{Potential screening tools}

For unidentified NIDDM:

- HbAlc

For impaired glucose tolerance and increased risk for cardiovascular disease:

- questionnaires + the assessment of waist-to-hip ratio, fasting levels of insulin, glucose and lipids

Box 6

form should be regarded as a selective high-risk approach. Obviously the sensitivity of the former approach is higher but the costs are enormous. The high-risk approach has a high specificity and the costs are consequently lower.

What is needed is a well-designed scenario for screening, which will enhance the efficiency of case finding. Several groups are now working on guidelines for such a screening approach based on the medical history, demographic and clinical information, and on fasting levels of metabolic parameters (glucose and serum lipids in particular). The factors which are assumed to be of predictive value for the existence of NIDDM are: family history of diabetes, (central) obesity, age $>40$ years, previously identified glucose intolerance, history of gestational diabetes, heavy babies $(>4500 \mathrm{~g})$, dyslipidaemia, hypertension, and Indian, black or hispanic ethnicity. ${ }^{28}$ To this list may be added prevalence of vascular and renal disease. A screening test should be simple, inexpensive, cause little discomfort or harm and be applicable for widespread use. Therefore, an oral glucose tolerance test, also because of its high within-subject variability, does not seem to be the instrument of choice. Although it is a good tool for epidemiologic research, where one is interested in prevalence or incidence rates of abnormal glucose tolerance in a large predefined population, it is not suitable for the assessment of glucose tolerance in an individual subject.

The prevention of complications is dependent on the degree of hyperglycaemia, whether measured as fasting or postload glucose, or as glycated haemoglobin (HbAlc). In populations with high diabetes prevalence rates, for example the Pima Indians, these three measures of glycaemia are equivalent as predictors of diabetic retinopathy. ${ }^{28}$ The major disadvantage of using $\mathrm{HbAl} \mathrm{c}$ as a screening tool are the poor standardisation of the various methods and the lack of long-term outcome data. Glycated haemoglobin may nevertheless be a good or even better tool for screening to identify subjects at risk for developing microvascular disease. However, it probably will not be an adequate tool for the identification of subjects at high-risk for developing cardiovascular disease, that is, subjects with the insulin-resistance syndrome and impaired glucose tolerance. To identify these high-risk subjects a different approach is required. The HbAlc measure is too insensitive as it does not discriminate between normal and impaired glucose tolerance. It will probably be necessary to raise public awareness and to train physicians to recognise high-risk subjects earlier. These are the persons with a high waist-to-hip ratio, a family history of cardiovascular disease and diabetes, and with dyslipidaemia and/or hypertension. Possible tools for the identification of these insulin-resistant persons are simple questionnaires combined with some blood measurements in the fasting state, eg, plasma glucose, triglycerides and insulin (box 6). As there are no data to support any of these scenarios it will require further studies.

Identification of undiagnosed diabetes and glucose intolerance/insulin resistance is only a starting point. Determining the optimal treatments and making them available to those who are identified will be the key issue and will prove to be the real challenge.

1 World Health Organization. Diabetes mellitus report of a WHO study group. Gene

2 Harris MI, Hadden WC, Knowler WC, Bennett $\mathrm{PH}$. Prevalence of diabetes and impaired glucose tolerance and plasma glucose levels in the US population aged 20-74 years. Diabetes 1987; 36: population

3 Tuomilehto J, Nissinen A, Kivelä SL, et al. Prevalence of diabetes mellitus in elderly men aged 65-84 years in eastern and western Finland. Diabetologia 1986; 29: 611-5.

4 Ohlson L-O, Larsson B, Eriksson H, Svärdsudd $\mathrm{K}$, Welin L, Tiblin G. Diabetes mellitus in Swedish middle aged men. The study of men born in 1913 and 1923. Diabetologia 1987; 30: 386-93.

5 Mooy JM, Grootenhuis PA, de Vries HA, et al. Prevalence and determinants of glucose intolerance in a Dutch Caucasian population: the Hoorn Study. Diabetes Care 1995; 18: 1270-3.

6 Klein R. Hyperglycaemia and microvascular and macrovascular disease in diabetes. Diabetes and macrovascular disea

7 Mogensen CE. Long term antihypertensive treatment inhibiting progression of diabetic nephropathy. $B M F$ 1982; 285: 685-8.

8 Harris MI. Undiagnosed NIDDM: clinical and public health issues. Diabetes Care 1993; 16: 642-53.
9 Beks PJ, Mackaay AJC, de Neeling JND, de Vries H, Bouter LM, Heine RJ. Peripheral arterial disease in relation to glycaemic level in an elderly Caucasion population: the Hoorn an elderly Caucasion population: the

16 Austin MA, Breslow JL, Hennekens $\mathrm{CH}$, Buring JE, Willett WS, Krauss RM. Low density lipoproteins subclass pattern and risk of myocarlipoproteins subclass pattern and risk of myocar-

17 Uusitupa MIJ, Niskanan LK, Siitonen O, et al. Ten year cardiovascular mortality in relation to Ten year cardiovascular mortality in relation to
risk factors and abnormalities in lipoprotein composition in type 2 (non insulin dependent) diabetic and non diabetic subjects. Diabetologia 1993; 36: 1175-84.

Harris MI, Klein RE, Welborn TA, Knuima MW. Onset of NIDDM occurs at least 4-7 years before clinical diagnosis. Diabetes Care 1992; 15: 815-9.

1 Sonnaville JJJ de, Feltz van der Sloot D van der, Ernst L, Wijkel D, Heine RJ. Retinopathy screening in Type II diabetes. Reliability of wide angle fundus photography. Diabetes Med, in press.

12 Jarrett RJ. Duration of non-insulin-dependent diabetes and development of retinopathy: analysis of possible risk factors. Diabetes Med 1986; 3: $261-3$.

13 Pyörälä K, Laakso $M$, Uusitupa $M$. Diabetes and atherosclerosis: an epidemiological view. and atherosclerosis: an epidemiological

14 Reaven GM, Laws A. Insulin resistance, compensatory hyperinsulinaemia, and coronary heart disease. Diabetologia 1994; 37: 948-52.

15 Ferrannini E, Haffner SM, Mitchell BD, Stern MP. Hyperinsulinaemia: the key feature of a cardiovascular and metabolic syndrome. Diabetologia 1991; 34: 416-22.

Fontbonne A, Eschwege E, Cambien F, et al. heart disease mortality in subjects with coronary glucose tolerance or diabetes. Results from the 11-year follow-up of the Paris Prospective Study. Diabetologia 1989; 32: 300-4.

19 Grootenhuis PA. Epidemiological aspects of the insulin resistance syndrome: the Hoorn study. Thesis, Vrije Universiteit, Amsterdam, 1994.

20 Eschwege E, Richard JL, Thibult N, et al. Coronary heart disease mortality in relation with diabetes, blood glucose, and plasma insulin levels, the Paris Prospective Study ten years later. Horm Metab Res 1985; 15 (suppl 1): 41-6. 
21 Jarrett RJ, Shipley MJ. Type II (non-insulin dependent) diabetes mellitus and cardiovascular disease, putative associations via common antecedents; further evidence from the Whitehall Study. Diabetologia 1988; 31: 737-40.

22 Jarrett RJ. Why is insulin not a risk factor for coronary heart disease. Diabetologia 1994; 37 : 945-7.

23 Fontbonne A, Thibult N, Eschwege E, Ducimetière $P$. Body fat distribution and coronary heart disease mortality in subjects with impaired glucose tolerance or diabetes mellitus: the Paris Prospective Study, 15 years follow-up. Diabetologia 1992; 35: 464-8.

24 Klein R. Hyperglycaemia and microvascular and macrovascular disease in diabetes. Diabetes Care 1995; 18: 258-68.
25 Kuusisto J, Mykkänan L, Pyöräla K, Laakso M. Non-insulin-dependent diabetes and its metabolic control predict coronary heart disease in elderly subjects. Diabetes 1994; 43: 960-7.

26 The Diabetes Control and Complications Trial Research Group. The effect of intensive treatment of diabetes on the development and progression of long-term complications in insulin dependent diabetes mellitus. $N$ Engl $\mathcal{f}$ Med 1993; 329: 977-86.

27 Garvey WT, Olefsky JM, Griffin J, Hamman Garvey $T$, Olefsky $J M$, Grifin $J$, Hamman RF, Kolterman OG. The effect of insulin treatment on insulin secretion and insulin action in type II diabetes mellitus. Diabetes 1985; 34:
222-34.
28 Knowler WC. Screening for NIDDM; opportunities for detection, treatment and prevention. Diabetes Care 1994; 17: 445-450.

29 Singh BM, Prescott JJW, Guy R, Walford S, Murphy M, Wise PH. Effect of advertising on awareness of symptoms of diabetes among the general public: the British Diabetic Association Study. BMF 1994; 308: 632-6. 